\title{
Summary of: Facilitation of implant provision in primary care
}

\author{
J. C. Field, ${ }^{1}$ N. Rousseau, ${ }^{2}$ J. M. Thomason, ${ }^{3}$ C. Exley, ${ }^{4}$ T. Finch, ${ }^{5}$ \\ J. G. Steele ${ }^{6}$ and J. S. Ellis ${ }^{7}$
}

\section{FULL PAPER DETAILS}

${ }^{1}$ Clinical Fellow in Restorative Dentistry, ${ }^{3}$ Professo of Prosthodontics and Oral Rehabilitation, ${ }^{7}$ Clinical Senior Lecturer, School of Dental Sciences, Newcastle University, Framlington Place, Newcastle, NE2 4AZ; ${ }^{2}$ Research Associate, ${ }^{4}$ Senior Lecturer in Medical Sociology, ${ }^{5}$ Senior Lecturer, ${ }^{6}$ Head of School and Professor of Oral Health Services Research, Institute of Health and Society, Newcastle

University, Newcastle NE1 7RU

${ }^{*}$ Correspondence to: James Field

Email: james.field@ncl.ac.uk

Online article number E20

Refereed Paper - accepted 22 June 2009

DOI: 10.1038/sj.bdj.2009.1013

${ }^{\circ}$ British Dental Journal 2009; 207: E20

Objective To investigate primary care practitioner participation in implant-supported mandibular overdenture (ISOD) provision. Design Postal questionnaire. Setting Primary dental care, North East England 2007. Subjects and methods Two hundred and ninety-five practitioners in North East England were sent questionnaires presenting a case-based scenario of a patient unable to manage a lower denture on an atrophic ridge. The questionnaire led them through the facilitation stages of ISOD provision, asking them to state their anticipated level of participation at each stage. Demographic details were also collected. Results Two hundred and seventeen responses were received (74\%). Most practitioners would consider the option of provision of ISODs (89\%) in this case and all who considered would discuss the option with the patient. Of those offering to facilitate treatment, 66\% (122/184) would never deliver themselves, with the majority $(60 \%$, $111 / 184)$ referring within primary care. Statistical analysis showed associations between demographics and behaviour. Conclusions The majority of practitioners in this study area would facilitate ISOD provision in this case. Practitioners who are male and working in a practice where a framework for the provision of implants already exists are most likely to facilitate provision and/or provide an ISOD within primary care.

\section{EDITOR'S SUMMARY}

At this year's British Society for the Study of Prosthetic Dentistry (BSSPD) annual conference, the panel of presenters and the BSSPD Council created the York Consensus Statement on implantsupported mandibular overdentures ${ }^{1}$ which concludes with the sentence 'There is now a large body of evidence that supports the proposal that a twoimplant supported mandibular overdenture should be the minimum offered to edentulous patients as a first choice of treatment.' Whether this treatment option is indeed the first choice offered to edentulous patients in the UK, particularly in primary care, has not so far been the subject of much investigation. This paper by Field et al. sets out to provide an initial analysis of primary care practitioners' approach to managing implant care, focusing on primary care dentists in North East England.

The majority of respondents indicated that they would facilitate implant provision in the case presented in the questionnaire, although 11\% would never consider them for that scenario. The results also suggested that the availability of implant treatment in primary care, at least in the study area, was limited: only 10\% of implant facilitating practitioners routinely provided the implants themselves, although most indicated that they would refer the patient to a primary care colleague. Male dentists working in a practice where there was an implant provider were found to be most likely to facilitate implant provision and to provide some part of the treatment themselves.

While the authors point out that dentists' decision making processes when faced with potential implant treatment are too complicated to be dealt with in a questionnaire survey such as this, the results nonetheless highlight some interesting associations between practitioners' facilitation behaviour and demographics. The main part of the larger study for which this paper provided the baseline data will provide much-needed elucida- tion of the complexities involved in this process - a better understanding that will hopefully contribute towards the goal of providing all edentulous patients with at least the option of implant-supported overdentures in future.

The full paper can be accessed from the $B D J$ website (www.bdj.co.uk), under 'Research' in the table of contents for Volume 207 issue 10.

1. Thomason J M, Feine J, Exley C et al. Mandibular two implant-supported overdentures as the first choice standard of care for edentulous patients - the York Consensus Statement. Br Dent J 2009; 207: 185-186.

Rowena Milan, Journal Editor DOI: 10.1038/sj.bdj.2009.1040 


\section{TO ACCESS THE BDJ WEBSITE TO READ THE FULL PAPER:}

- BDA Members should go to www.bda.org.

- Click the 'login' button on the right-hand side and enter your BDA login details.

- Once you have logged in click the 'BDJ' tab to transfer to the BDJ website with full access.

IF YOUR LOGIN DETAILS DO NOT WORK:

- Get a password reminder: go to www.bda.org, click the login button on the right-hand side and then click the forgotten password link.

- Use a recommended browser: we recommend Microsoft Internet Explorer or Mozilla Firefox.

- Ensure that the security settings on your browser are set to recommended levels.

IF YOU HAVE NOT YET SIGNED UP TO USE THE BDA WEBSITE:

- Go to www.bda.org/getstarted for information on how to start using the BDA website.
IN BRIEF

- Allows readers to appreciate the level of facilitation of implant provision within primary care.

- Highlights the need for informed consent when treatment planning for the edentulous patient.

- Promotes the implant-supported overdenture as an effective treatment option for the edentulous patient.

- Emphasises the need for further qualitative research into the decision-making process.

\section{COMMENT}

Dental health education has taken great strides over the past 30 years and fortunately, this is evidenced by significantly greater numbers of older patients retaining natural teeth. Regrettably however, many are still edentulous and as the edentulous ridges reduce, so has the experience of many general dental practitioners. An increasingly prevalent outcome is lack of success with complete denture wearing. The development of implant-stabilised removable complete dentures has led to increased levels of success and this has raised expectations among the edentulous population.

This study investigated, via a questionnaire, the views of general dental practitioners in the North East of England on a clinical scenario of an edentulous patient with well made dentures but with an atrophic mandibular ridge. No medical history was given, nor was any denture-wearing history offered, but the authors attempted to follow the guidelines suggested in the McGill consensus statement of 2002.

An impressive 74\% (out of 295 practitioners) responded and it was interesting that most practitioners (89\%) would consider the option of implant-stabilised overdentures (termed implantsupported overdentures - ISOD - by the authors) and these practitioners stated that they would discuss the option with the patient. However, out of those who would include implants as a treatment option, only $66 \%$ would not deliver this themselves with $60 \%$ stating that they would refer to colleagues within primary care. Obvious differences between referring-on patterns existed between males and females and also between practitioners over and under the age of 50.

This excellent article has highlighted that if ISODs are to be provided within primary care under NHS regulations, then greater training needs need to be met and, of perhaps greater importance, a radical overview is required of how such treatment might be more efficiently made available on the NHS.

\section{F. McCord}

Professor of Restorative Dentistry and Honorary Consultant in Restorative Dentistry, Glasgow Dental Hospital and School

\section{AUTHOR QUESTIONS AND ANSWERS}

1. Why did you undertake this research? This study was part of a larger Medical Research Council-funded project. The broader aim was to investigate how clinicians and patients negotiate clinical need and treatment decisions within a context of finite resources. Within the UK, little is known about the influence of practitioner characteristics on their facilitation of, and referral for, more specialist treatments. This first phase study provided baseline data about existing practice in relation to dental implant treatment in the North East of England. The data allowed initial analysis of the relationship between individual characteristics and demographics of primary care practitioners and their approach to managing implant care.

2. What would you like to do next in this area to follow on from this work?

The data on current practice was subsequently used to identify practitioners and patients for recruitment to the main part of the study. This involved qualitative research methods such as semistructured interviewing to gain a rich and deeper understanding of the decision making process. The results of this study are forthcoming. 